\title{
PERANG BALKAN 1, 1912-1913: ANALISIS DARI REKOD-REKOD BRITISH
}

\author{
Azlizan Mat Enh
}

\begin{abstract}
The first Balkan war, which was triggered by the Balkan states like Serbia, Montenegro and Bulgaria against the Ottoman Turkish government in 1912, marked an important milestone in the history of the world and Eastern Europe in particular. This is because although the Balkan War negotiation was successfully agreed at the international negotiating table by the great powers of Europe, it became a prelude to World War 1. The victory of Serbia against the Ottoman Turkish government in 1913 in the Balkan War had given the motivation for the small Balkan states to be involved in conflicts in Sarajevo in 1914, which eventually caused the outbreak of World War 1. This article discusses the factors that led these small Balkan states to oppose the Ottoman Turkish government and the resolution that was undertaken to end these conflicts. The analysis of this discussion are based on the primary sources obtained from the British ambassadors in the Balkans, which are held in the National Archives in Kew, London. The study found that the desire to defeat the Ottoman Empire by these small Balkan states and the desire to take over the position of the Ottoman power in the Balkans were the main causes for the war.
\end{abstract}

\section{Pengenalan}

Perang Balkan yang meletus pada tahun 1912 sehingga 1913 adalah berhubung kait dengan pengambilan Bosnia-Herzegovina oleh 
Austria-Hungary pada tahun 1908 tanpa restu daripada negeri-negeri Semenanjung Balkan. Keputusan tersebut telah mendatangkan dendam kepada bangsa Slav khususnya Serbia. Serbia yang mengharapkan Bosnia-Herzegovina diserahkan kepadanya merasa kecewa dengan keputusan Austria-Hungary. Selain Serbia, Bulgaria juga masih menyimpan rasa tidak puas hati dengan Perjanjian Berlin 1878 yang mengecilkan wilayah Bulgaria daripada cadangan asal Perjanjian San Stefano. Kejayaan Bulgaria mendapatkan kemerdekaan daripada Uthmaniyah memberi inspirasi kepada Bulgaria untuk menambahkan semula saiz wilayah Bulgaria. Tambahan pula, Rusia juga tidak berpuashati dengan pengambilan Bosnia-Herzegovina oleh AustriaHungary. Tindakan Austria-Hungary itu bukan sahaja memalukan Serbia tetapi juga Rusia. Pada Rusia, kejayaan Austria-Hungary ke atas Bosnia-Herzegovina merupakan ancaman kepada pengaruh Rusia di Balkan. Perkara ini bukan sahaja menjadi pesaing kepada Rusia sebaliknya juga merupakan ancaman kepada Serbia untuk pembentukan Serbia Raya. Pada Serbia, mereka perlu bersaing dengan Austria-Hungary untuk mendapatkan wilayah-wilayahSlav yang masih berada dalam pentadbiran kerajaan Uthmaniyah sebelum wilayah tersebut jatuh ke tangan Austria-Hungary. Oleh itu, isu pengambilan Bosnia-Herzegovina ini telah mencetuskan kebangkitan kepada Serbia dengan mendapat galakan daripada Rusia.

Bagi merealisasikan cita-cita Serbia dan Rusia sendiri, Rusia telah membantu Serbia untuk mendapatkan sokongan daripada jiranjirannya di Semenanjung Balkan. Antara negeri Balkan yang bersedia untuk berjuang dengan Serbia ialah Bulgaria. Ini kerana Bulgaria bercita-cita untuk membebaskan dan menakluki Macedonia daripada Uthmaniyah serta mendapatkan wilayah Adrianople. Bulgaria yang kecewa dengan keputusan di Berlin telah bersetuju untuk membentuk pakatan dengan Serbia. Rusia yang memusuhi Austria-Hungary supaya tidak terlalu berpengaruh di Balkan telah memainkan peranan menyatu dan menganjurkan pakatan ketenteraan di negeri-negeri Balkan untuk membentuk Liga Balkan. Penyatuan kuasa-kuasa kecil Balkan di bawah Liga Balkan telah membawa kepada tercetusnya Perang Balkan di Semenanjung Balkan dengan kerajaan Uthmaniyah.

\section{Pembentukan Liga Balkan}

Idea kepada pembentukan Liga Balkan ini telah wujud pada penghujung tahun 1911 dan hanya terbentuk pada Mac 1912. Ini merupakan satu pakatan ketenteraan dan politik di negeri-negeri di Semenanjung Balkan yang terdiri daripada Serbia, Bulgaria, Montenegro dan Greek. Pakatan Balkan ini dianjur dan dipengaruhi oleh Rusia. ${ }^{1}$ Tujuan utama 
penubuhan Liga Balkan kerana Rusia menentang pemerintahan Austria-Hungary di Balkan. ${ }^{2}$ Antara negeri Balkan yang pertama menandatangani perjanjian persefahaman ini ialah Serbia dan Bulgaria pada 29 Februari 1912. ${ }^{3}$

Antara isi kandungan lain yang termaktub dalam perjanjian kedua-dua negeri itu ialah masing-masing bersetuju untuk bergabung dan saling membantu apabila salah satu daripada mereka diserang. Selain itu, mereka juga bersepakat untuk bertindak menentang kerajaan Uthmaniyah sekiranya berlaku sebarang perubahan status quo di Semenanjung Balkan yang boleh menggugat kepentingan peribadi mereka. Kedua-duanya telah berbincang mengenai pembahagian sempadan di wilayah Uthmaniyah di Macedonia sekiranya mereka berjaya mengalahkan kerajaan Uthmaniyah. Mengikut perjanjian yang dipersetujui, Serbia akan memperolehi bahagian utara Macedonia manakala selebihnya akan diserahkan kepada Bulgaria. Sekiranya, kedua-dua mereka tidak dapat mencapai kata sepakat mengenai pembahagian wilayah, maka mereka akan merujuk kepada Rusia sebagai perantaranya. ${ }^{4}$

Pada 29 Mei 1912, Greek pula telah membuat perjanjian dengan Bulgaria. Masing-masing bersetuju untuk memberi bantuan ketenteraan sekiranya mereka diserang oleh kerajaan Uthmaniyah. Selain itu, Bulgaria juga bersetuju bahawa operasi peperangan tidak akan melibatkan wilayah Crete. ${ }^{5}$ Walau bagaimanapun, perjanjian antara kedua-dua kuasa kecil ini tidak membincangkan mengenai pembahagian wilayah di Balkan. Perjanjian yang sama seterusnya ditandatangani antara Serbia dan Greek pada April, 1912. ${ }^{6}$ Raja Montenegro ${ }^{7}$ yang telah lama bercitacita memusuhi kerajaan Uthmaniyah turut membuat perjanjian yang sama dengan Serbia, Greek dan Bulgaria. Maka dengan penyertaan dan pakatan keempat-empat negeri ini, maka terbentuklah Liga Balkan.

\section{Perang Uthmaniyah - Itali 1912}

Perang Uthmaniyah-Itali yang meletus pada tahun 1911, turut menyumbang kepada meletusnya Perang Balkan. Ini kerana, mereka bimbang sekiranya Itali menang dalam peperangan tersebut dan mampu menawan Tripoli. ${ }^{8}$ Sekiranya Itali berjaya mendapatkan Tripoli daripada kerajaan Uthmaniyah, Itali boleh meluaskan kuasanya di Balkan dengan memasuki sebahagian daripada Albania yang masih berada di bawah pemerintahan kerajaan Uthmaniyah. Kedudukan Albania di Balkan adalah penting kerana Albania mempunyai laluan ke Adriatik. Serbia yang telah lama bercita-cita untuk mendapatkan laluan ke Adriatik tidak akan mengizinkan Itali mendapatkan Albania. Di samping itu, 
sekiranya Albania berjaya diletakkan di bawah pengaruh Itali, maka ini boleh merubah kedudukan status quo di Semenanjung Balkan.

Di samping itu, Serbia juga mencurigai Itali dan Austria-Hungary sekiranya terdapat perjanjian antara mereka mengenai Sanjak Novi Bazar di Bosnia. Austria-Hungary telah mempunyai perjanjian dengan Itali mengenai Tripoli. Ini kerana, Austria-Hungary telah bersetuju membenarkan perluasan kuasa Itali di Tripoli. Austria-Hungary menegaskan bahawa Austria-Hungary tidak akan menghalang perluasan kuasa Itali di Tripoli dan tidak akan terlibat dalam peperangan antara Itali dan kerajaan Uthmaniyah. Oleh itu, keizinan yang diberikan oleh Austria-Hungary kepada Itali membimbangkan Serbia. Sekiranya mereka bekerjasama dengan Austria-Hungary, Itali mula mengizinkan penaklukan Austria-Hungary ke atas Sanjak Novi Bazar. Ini kerana Sanjak Novi Bazar masih merupakan wilayah Uthmaniyah di BosniaHerzegovina. Selain Sanjak, Montenegro dan Serbia juga merupakan antara wilayah perhubungan antara negeri-negeri tersebut dengan Bosnia-Herzegovina.

Selain itu, negeri-negeri Balkan seperti Serbia dan Bulgaria turut menyedari bahawa Perang Uthmaniyah-Itali ini telah melemahkan kerajaan Uthmaniyah. Serbia yakin bahawa sekiranya meletus peperangan di Balkan antara negeri-negeri Balkan dengan kerajaan Uthmaniyah, kerajaan Uthmaniyah tidak akan berjaya menghadapinya. Ini kerana tentera-tentera Uthmaniyah tidak dapat bersedia dan pulih sepenuhnya daripada peperangan dengan Itali. Oleh itu, ini merupakan peluang yang baik kepada mereka untuk bertindak ke atas wilayah kerajaan Uthmaniyah di Balkan seperti di Macedonia. Oleh itu, adalah wajar kepada negeri Balkan ini untuk bersatu dan sepakat di bawah Liga Balkan.

\section{Sokongan Rusia kepada Liga Balkan}

Selepas penyerahan seraca rasmi Bosnia-Herzegovina kepada AustriaHungary pada 1908, peristiwa tersebut telah mendatangkan kekecewaan dan kebimbangan tentang pengaruh Rusia di Balkan. Ini kerana kejayaan Austria-Hungary mendapatkan Bosnia-Herzegovina telah menggugat pengaruh dan kewibawaan Rusia sebagai pembela Slav di Semenanjung Balkan. Selain itu, peristiwa tersebut juga telah menjatuhkan imej dan maruah Rusia kerana gagal menyelamatkan negeri Slav daripada dikuasai oleh bangsa Magyar. Oleh itu, polisi Rusia di Balkan yang utama adalah untuk menyekat dan menghalang pengaruh AustriaHungary di Balkan. Rusia ingin mengekalkan pengaruhnya sebagai pelindung bangsa Slav di Eropah. ${ }^{9}$ 
Oleh yang demikian, salah satu cara untuk mencapai cita-cita Rusia ini adalah dengan menggunakan negeri-negeri Balkan terutamanya Serbia untuk menentang Austria-Hungary. Pembentukan Liga Balkan merupakan satu-satunya kekuatan Rusia untuk melemahkan AustriaHungary. Rusia telah merahsiakan pakatan dan perjanjian yang ditermeterai antara Serbia dan Bulgaria tanpa pengetahuan kuasakuasa besar. ${ }^{10}$ Rusia berharap agar dengan pembentukan Liga Balkan, negeri-negeri Balkan akan memperjuangkan semangat nasionalisme Slav di Balkan dan akan menghalau Austria-Hungary daripada wilayah mereka di Balkan. ${ }^{11}$

Kerajaan Rusia juga telah memberikan galakkan kepada Serbia dan Bulgaria supaya meneruskan tuntutan terhadap pelaksanaan reformasi di Macedonia. Setelah kerajaan Uthmaniyah berjanji untuk memberikan taraf wilayah autonomi kepada Albania, Rusia telah mendesak supaya Serbia dan Bulgaria turut meminta hak yang sama ke atas Macedonia. ${ }^{12}$ Duta Rusia di Macedonia telah menggembar-gemburkan isu bahawa autonomi hanya diberikan kepada Albania dan kerajaan Uthmaniyah kerana telah mengabaikan orang Kristian di Macedonia. Ini secara langsung telah memburukkan keadaan di Balkan dan mencetuskan sikap anti Uthmaniyah di Bulgaria.

Selain itu, Rusia juga tidak menyetujui cadangan daripada Count Berchtold mengenai desentralisasi di Albania. Ini kerana, menurut Menteri Luar Rusia iaitu M Sazanov, tindakan Count Berchtold itu menunjukkan bahawa Austria-Hungary ingin bekerja sendirian dan membelakangkan Rusia. Tujuan Count Berchtold itu dianggap sebagai ingin menghapuskan status Rusia sebagai pelindung Slav di samping ingin merendahkan prestij Rusia dalam kalangan Slav di Balkan. Oleh itu, pada pandangan Rusia, masalah di Balkan seharusnya diselesaikan oleh semua kuasa-kuasa besar dan bukan sekadar menerima cadangan daripada Austria-Hungary.

Selain itu, Rusia juga menolak cadangan Austria-Hungary kerana Rusia sedar bahawa cadangan desentralisasi Austria-Hungary itu merupakan salah satu langkah untuk memberikan taraf autonomi kepada Albania. Walau bagaimanapun, Rusia tidak mampu menerimanya kerana sekutunya di Balkan iaitu Bulgaria dan Serbia tidak ingin melihat Albania sebagai wilayah berautonomi. Mereka ingin Albania kekal di bawah pentadbiran kerajaan Uthmaniyah, supaya Albania dijadikan sebagai contoh kelemahan pentadbiran kerajaan Uthmaniyah di Balkan. Sekiranya Muslim Albania mendapat semi kemerdekaan atau diberikan autonomi, Albania akan menjadi tunggak kekuatan kerajaan Uthmaniyah di Balkan. Oleh itu, mereka ingin Albania terus menjadi negeri yang kucar kacir di Balkan. ${ }^{13}$ Disebabkan perkara yang berlaku, Rusia mengingatkan agar kuasa-kuasa besar bahawa pemberian taraf 
autonomi di Albania akan mendatangkan bahaya di Balkan. Ini kerana, menurut Rusia semi kemerdekaan yang akan diberikan kepada Albania akan meransangkan keganasan di Macedonia. Malah, Rusia juga sedar bahawa cadangan Austria-Hungary itu dianggap akan melumpuhkan pakatan Serbia dan Bulgaria.

Pada dasarnya, tujuan Rusia adalah untuk mendapatkan Selat Bosphorus dan Dardanelles. Ini merupakan tujuan utama Rusia memberikan sokongan kepada pembentukan Liga Balkan ini. Walau bagaimanapun, Rusia mendapati kedudukannya tergugat apabila kuasa-kuasa kecil ini semakin kuat dan sukar dikawal terutamanya Bulgaria. Rancangan-rancangan yang dilakukan oeh Rusia mula dihidu oleh Bulgaria. Bulgaria ingin menawan Adrianople dan tenteranya akan mara untuk menakluki Constantinople. Walau bagaimanapun, Rusia tidak mengizinkan cita-cita untuk menawan Constantinople. Ini kerana, Rusia bimbang tindakan tersebut boleh mengubah kedudukan status quo di Eropah.

Selain itu, sekiranya Bulgaria berjaya menakluki Constantinople ini bermakna Selat Dardanelles dan Bosphorus akan berada di bawah kekuasaan Bulgaria. Ini akan memusnahkan cita-cita Rusia yang selama ini ingin menguasai selat-selat tersebut. Justeru, Rusia perlu menghalang Bulgaria daripada mara ke Constantinople. ${ }^{14}$ Walau bagaimanapun, Rusia dengan tegas melarang Bulgaria dan sekutunya memasuki Constantinople sebaliknya mengekalkan keamanan dan tidak melancarkan serangan kepada kerajaan Uthmaniyah tanpa kebenaran Rusia. Rusia juga telah memberikan amaran kepada kuasa-kuasa kecil Balkan bahawa Rusia tidak akan menyokong mereka sekiranya mereka membuat serangan:

Russian Minister tells me that two days ago he presented, a memorandum stating that if Balkan States commenced war, Russia would leave them to their fate, and urging Servian government to inform Bulgaria government that they would dissociate themselves from aggressive action. ${ }^{15}$

Pada 20 September, Rusia cuba menggunakan pengaruhnya ke atas Belgrade dan Bulgaria agar dapat menghalang tindakan Bulgaria. Namun usaha Rusia ini tidak mendapat reaksi daripada Serbia. Bulgaria dan Serbia berasa kecewa dengan Rusia yang selama ini berusaha menyatukan mereka dan kini cuba memisahkan Liga Balkan. ${ }^{16}$ Menurut Raja Ferdinand, peperangan antara kuasa-kuasa Balkan dengan kerajaan Uthmaniyah tidak dapat dielakkan lagi, melainkan kerajaan Uthmaniyah memenuhi tuntutan mereka dengan meletakkan pemimpin Kristian di wilayah jajahan kerajaan Uthmaniyah di Balkan atau pelantikan tersebut dengan jaminan kuasa-kuasa besar Eropah. ${ }^{17}$ 
Akibat masalah yang semakin meruncing di Balkan dan kegagalan Rusia untuk menggunakan diplomasinya untuk mengamankan kuasakuasa kecil daripada menyerang kerajaan Uthmaniyah, ini telah menyebabkan Rusia memohon bantuan daripada semua kuasa-kuasa Eropah untuk mengadakan rundingan dan bekerjasama bagi mengatasi masalah di Balkan. Walau bagaimanapun, kuasa-kuasa besar yang lain telah menasihati Rusia dan Austria-Hungary supaya bersama-sama berbincang dan mengusulkan cadangan kepada kerajaan Uthmaniyah agar dapat menghalang peperangan di Balkan dengan kerajaan Uthmaniyah. Langkah yang diputuskan oleh Poincare ini bertujuan untuk mengelakkan konflik dan peperangan antara kedua-dua kuasa besar itu di Balkan.

Ini kerana peperangan antara kuasa-kuasa kecil di wilayah-wilayah jajahan Uthmaniyah di Balkan boleh mengheret Austria-Hungary dan Rusia untuk terlibat sama dan akan mengancam keamanan di Eropah. Ini kerana, Rusia dan Austria-Hungary mempunyai kepentingan yang sama di Semenanjung Balkan berbanding kuasa-kuasa Eropah yang lain. Oleh itu, pada pendapat Poincare adalah wajar kedua-dua kuasa besar itu diberikan mandat sebagai pengantara kepada masalah di Balkan. ${ }^{18}$ Pendapat tersebut diterima oleh semua kuasa besar lain termasuk Rusia dan Austria-Hungary.

Pada 8 Oktober 1912, Rusia dan Austria-Hungary bersetuju untuk memutuskan beberapa perkara supaya diberi perhatian oleh kerajaan Uthmaniyah. Antaranya kuasa-kuasa besar tidak dibenar memecahbelahkan keadaan dan keamanan di Eropah. Reformasi di Macedonia akan dilaksanakan di bawah pengawasan Rusia dan AustriaHungary. Sekiranya peperangan meletus di Eropah, mana-mana kuasa tidak boleh membuat sebarang perubahan kepada status quo di Balkan. ${ }^{19}$ Namun begitu, diplomasi ini tidak dapat dilaksanakan dengan sepenuhnya apabila Montenegro mengisytiharkan perang ke atas kerajaan Uthmaniyah beberapa jam sebelum itu. Walaupun Montenegro telah dinasihati bahawa kuasa-kuasa besar akan menanggani permasalahan di Balkan, namun mereka enggan menerima sebaliknya ingin menyelesaikannya sendiri dengan kerajaan Uthmaniyah.

Perkara ini menunjukkan polisi kerajaan Rusia di Balkan tidak begitu konsisten. Walaupun pada hakikatnya, Rusia menggalakkan penentangan kuasa-kuasa Balkan ke atas kerajaan Austria-Hungary dan kerajaan Uthmaniyah, namun Rusia tidak sanggup melihat kekuatan dan persefahaman dalam kalangan kuasa-kuasa Balkan terutamanya Serbia dan Bulgaria. Dari satu segi, Rusia turut berada dalam keadaan dilema, kerana memisahkan Serbia dan Bulgaria. Ini bermakna mengikis dan menghapuskan perpaduan antara bangsa Slav yang mana akan melibatkan kelumpuhan kepada Rusia di Balkan. ${ }^{20}$ Namun begitu, 
pada Rusia peperangan di Eropah harus dielakkan kerana Rusia sendiri tidak mahu terlibat dalam konflik dengan Austria-Hungary yang boleh menggugat status quo di Balkan. Keadaan-keadaan seperti ini telah menyebabkan polisi Rusia di Balkan tidak konsisten.

\section{Semangat Nasionalisme di Balkan}

Salah satu faktor utama yang menjadi tunggak kepada tercetusnya Perang Balkan pada 1912 berpunca daripada dendam yang tidak kesudahan di Balkan terutamanya Serbia dan Bulgaria. Kedua-dua kuasa kecil ini tidak berpuas hati sejak keputusan Perjanjian Berlin 1878 yang membawa kerugian kepada mereka. Kedua-dua kuasa ini telah menyokong Rusia semasa Perang Rusia-Uthmaniyah 1877-1878 dengan harapan untuk mendapatkan lebih kuasa dan pengaruh di Balkan. Namun begitu, mereka kecewa dengan keputusan kuasa-kuasa Besar yang telah membelakangkan inspirasi dan cita-cita mereka.

Bulgaria tidak berpuas hati dengan keputusan di Berlin yang telah mengecilkan wilayah Bulgaria daripada cadangan asal Perjanjian San Stefano. Melalui Perjanjian San Stefano, Rusia memperuntukkan wilayah Macedonia kepada Bulgaria. Namun, keputusan ini tidak dipersetujui oleh kuasa-kuasa besar lain sehingga mendorong kepada termeterainya Perjanjian Berlin yang mengembalikan semula wilayah Macedonia kepada kerajaan Uthmaniyah serta mengecilkan saiz Bulgaria. Di samping itu, Bulgaria juga secara sulit merancang untuk menawan Constantinople sekiranya mereka menang dalam peperangan dengan kerajaan Uthmaniyah. Oleh itu, Bulgaria masih bercita-cita untuk mendapatkan semula bahagian selatan Macedonia.

Sementara itu, Serbia pula tidak berpuas hati apabila BosniaHerzegovina diserahkan kepada kerajaan Austria-Hungary dalam Perjanjian Berlin 1878 dalam krisis Bosnia 1909. Kerajaan Serbia sanggup melakukan apa sahaja untuk mendapatkan Bosnia-Herzegovina bagi menjayakan cita-citanya membentuk Serbia Raya. Sekiranya Serbia berjaya menawan Macedonia, Serbia berjanji akan mendapat bahagian utara Macedonia oleh Bulgaria. Sekiranya Bulgaria secara sulit merancang untuk mendapatkan Constantinople, Serbia juga berazam untuk meneruskan penguasaannya terhadap wilayah Uthmaniyah di Albania seperti di Kosovo dan sebahagian daripada wilayah Monastir di Macedonia dan pelabuhan San Giovanni yang terletak di Adriatik. ${ }^{21}$ Perkara ini bertujuan mendapatkan laluan ke Laut Adriatik. Oleh itu, kedua-dua negeri Balkan ini mempunyai asas yang cukup kuat untuk bersatu menentang kerajaan Uthmaniyah di Macedonia.

Oleh kerana dendam dan tidakpuas hati antara kuasa-kuasa kecil Balkan, menyebabkan mereka mencari peluang dan alasan untuk 
lebih berkuasa di Semenanjung Balkan. Bagi mencapai matlamat tersebut, Bulgaria telah mencetuskan isu kelemahan pentadbiran dan pemerintahan Uthmaniyah di Macedonia. Kerajaan Uthmaniyah dikatakan menindas orang Kristian. Isu tersebut dijadikan alasan untuk menunjukkan ketidakadilan pentadbiran kerajaan Uthmaniyah di Macedonia. Bulgaria menggunakan peluang tersebut sebagai alasan untuk menuntut bela ke atas bangsa Kristian. Antaranya, Bulgaria mendakwa bahawa kerajaan Uthmaniyah tidak mengambil sebarang tindakan untuk memperbaiki kebajikan orang Kristian sepertimana orang Muslim di Albania. Bulgaria juga menuntut supaya orang Kristian di Macedonia diberikan konsesi yang sama sepertimana yang diperoleh oleh orang Muslim di Albania. ${ }^{22}$

Pernyataan tersebut telah mendapat tindak balas daripada kerajaan Uthmaniyah. Kerajaan itu tidak dapat menerima tuntutan yang dikemukakan oleh Bulgaria. Namun begitu, kerajaan Uthmaniyah memberikan jaminan bahawa mereka sedang berusaha melaksanakan reformasi di Macedonia untuk memperbaiki keadaan di sana. Adalah sukar kepada kerajaan Uthmaniyah untuk melaksanakan reformasi di Macedonia dengan berkesan dalam tempoh yang singkat kerana negeri itu sedang berada dalam keadaan kucar kacir dan campurtangan pelbagai pihak yang tidak membantu menyelesaikan masalah. ${ }^{23}$

Selain Bulgaria, Montenegro juga menggunakan pengaruhnya dalam kalangan orang Kristian di Albania. Apabila penduduk di Albania memberontak terhadap kerajaan Uthmaniyah pada 1911 kerana tidak berpuashati dengan sistem pungutan cukai yang diperkenalkan oleh Djavid Pasha, kerajaan Montenegro telah memberi kerjasama membantu pemberontak-pemberontak tersebut. Mereka telah mendapat bekalan senjata daripada Montenegro.

Selain memusuhi kerajaan Uthmaniyah, Montenegro juga bercitacita untuk menggantikan Serbia di Balkan sebagai penaung kepada bangsa Slav. Oleh yang demikian, walaupun kerajaan Uthmaniyah memperkenal dan melaksanakan reformasi di Albania, namun permusuhan terhadap kerajaan Uthmaniyah tetap berterusan kerana aktiviti dalaman dan galakan daripada Montenegro. ${ }^{24}$ Pada 19 Ogos 1912, kerajaan Montenegro telah membuat provokasi di wilayah Berana, Albania. Tentera Montenegro menyeberang sempadan dengan alasan untuk melindungi orang Kristian di Albania. Menurut kerajaan Montenegro, orang Muslim telah menyerang orang Kristian. Walau bagaimanapun, ini merupakan helah Montenegro untuk menimbulkan rusuhan antara Muslim dan Kristian di wilayah tersebut. Tindakan yang dilakukan oleh Montenegro disokong oleh sekutunya Bulgaria. Suratkhabar Bulgaria menggesa kuasa-kuasa besar supaya bertindak 
melindungi nasib-nasib orang Kristian yang berada di bawah pentadbiran kerajaan Uthmaniyah seperti di Albania dan Macedonia. ${ }^{25}$

Sebagai balasan, kerajaan Uthmaniyah memberi jaminan kepada Bulgaria bahawa kerajaannya akan membawa keamanan dengan segera di Macedonia dan Albania tanpa berlengah-lengah lagi. Malah, kuasakuasa besar turut memberi jaminan kepada Bulgaria bahawa mereka akan memastikan reformasi di wilayah Uthmaniyah akan dilaksanakan dengan berkesan. ${ }^{26}$ Namun begitu, Bulgaria tidak mendengar nasihat daripada kuasa-kuasa besar sebaliknya memberi kata dua kepada kerajaan Uthmaniyah dalam tempoh 24 jam pada 7 Oktober 1912. Dalam kata dua itu, Bulgaria telah mengemukakan beberapa tuntutan kepada kerajaan Uthmaniyah. Antaranya, mereka mendesak kerajaan Uthmaniyah supaya ketua di Macedonia terdiri daripada orang Kristian dan bukan lagi orang Muslim seperti yang diamalkan sebelum ini. Kedua, Bulgaria juga menuntut supaya Macedonia diberikan hak wilayah berautonomi di bawah perlindungan kuasa-kuasa besar. Ketiga, reformasi yang akan diperkenalkan oleh kerajaan Uthmaniyah di Macedonia seharusnya dilaksanakan dengan berkesan. Selain itu, Bulgaria juga memberi amaran kepada kerajaan Uthmaniyah bahawa kelewatan membalas kata dua ini akan menyebabkan keempat-empat anggota Liga Balkan iaitu Bulgaria, Serbia, Greek dan Montenegro akan mengisytiharkan perang serentak ke atas kerajaan Uthmaniyah. ${ }^{27}$ Kata dua tersebut disampaikan kepada duta kerajaan Uthmaniyah di Athens, Belgrade, Cettinje dan Sophia.

Walau bagaimanapun, sebelum sempat kerajaan Uthmaniyah membalas kata dua tersebut, kerajaan Montenegro membuat keputusan dengan sendirinya mengisytiharkan perang ke atas kerajaan Uthmaniyah pada 9 Oktober 1912 ketika kuasa-kuasa besar sedang mengatur rundingan keamanan dengan kerajaan Uthmaniyah berhubung isu Balkan. Peperangan yang dilancarkan oleh Montenegro ini dibuat tanpa berunding dengan kuasa-kuasa besar yang lain termasuk Rusia. ${ }^{28}$ Tindakan Montenegro kemudiannya diikuti oleh Bulgaria dan Greek yang turut mengisytiharkan perang terhadap kerajaan Uthmaniyah pada 17 Oktober 1912 yang kemudiannya diikuti oleh Serbia. ${ }^{29}$ Maka kerajaan Uthmaniyah tidak mempunyai pilihan selain terpaksa mengisytiharkan perang ke atas keempat-empat negeri Balkan tersebut.

Menteri Bulgaria sendiri menegaskan bahawa persetujuan antara Bulgaria, Serbia, Greek dan Montenegro telah dicapai sepenuhnya. Mereka bersedia untuk menyerang kerajaan Uthmaniyah untuk mempercepatkan peperangan antara kerajaan Uthmaniyah sepertimana dilaporkan oleh duta Britain di Belgrade "The Balkan States desire to push matters as far as possible short of actual war". ${ }^{30}$ 
Peperangan yang berlaku secara langsung mendatangkan kesukaran kepada kerajaan Uthmaniyah yang belum bersedia sepenuhnya kerana sedang menghadapi Itali dalam peperangan Tripoli. Manakala kuasa-kuasa kecil Balkan seperti Serbia berazam untuk terus mara tanpa kompromi dan nekad untuk mendapatkan negeri-negeri Balkan Uthmaniyah. Masing-masing mempunyai agenda tersendiri terhadap wilayah yang ingin dirampas daripada kerajaan Uthmaniyah. Bagi meneruskan perancangan, mereka mula menempatkan tentera mereka di wilayah tertentu di Balkan. Bagi Bulgaria, negara ini berkeinginan menguasai Macedoni manakala Serbia pula berkeinginan menawan Albania agar mendapat laluan ke Laut Adriatik. ${ }^{31}$ AustriaHungary pernah berjanji kepada Rusia pada 1908 bahawa sekiranya Austria-Hungary berjaya mendapat Bosnia-Herzegovina kerajaan tersebut bersetuju untuk membahagikan wilayah Sanjak Novi Bazar kepada Serbia dan Montenegro. ${ }^{32}$ Namun hasrat tersebut tidak dapat ditunaikan apabila kuasa-kuasa besar yang lain bersetuju mengekalkan wilayah tersebut di bawah kedaulatan kerajaan Uthmaniyah. Bagi Greek pula, hasrat yang dibawa adalah untuk mendapatkan kemerdekaan ke atas Crete yang gagal diperolehi semasa perang Greek-Uthamaniah pada 1883.

\section{Perang Balkan 1}

Pada 22 Oktober, Bulgaria berjaya menyerang Kirkkilise iaitu bahagian utara Adrianople. Serangan ini membawa kejayaan yang cemerlang kepada Bulgaria apabila memperoleh kejayaan pertama menawan kota tersebut pada 24 Oktober dalam tempoh dua hari. Kejayaan tentera Bulgaria ini berulang lagi apabila mereka berjaya mengalahkan tentera Uthmaniyah dan menawan beberapa kota di bahagian timur dan barat Adrianople. Kejayaan demi kejayaan yang dicapai secara langsung memudahkan mereka untuk menceroboh Adrianople. Adrianople ialah kubu utama kerajaan Uthmaniyah di Eropah. Sekiranya Adrianople tewas ke tangan tentera Bulgaria maka kedudukan Constantinople akan tergugat. Ini kerana, Adrianople penting kepada Bulgaria untuk mencapai cita-citanya membentuk Bulgaria Raya yang gagal diperolehinya melalui Perjanjian San Stefano.

Kejayaan ini membimbangkan kerajaan Uthmaniyah. Pada 3 November 1912, Gabriel Effendi iaitu Menteri Luar Uthmaniyah telah membuat permintaan kepada duta Perancis di Constantinople untuk mengajukan kepada kuasa-kuasa besar supaya campurtangan dan menjadi perantara di antara kerajaannya dengan negeri-negeri Balkan supaya dapat mengadakan gencatan senjata. ${ }^{33}$ Namun, permintaan tersebut telah ditolak dengan angkuh oleh kerajaan Bulgaria. Bagi 
Bulgaria, perjuangan yang sebenar setelah mereka berjaya menguasai Adrianople dan Constantinople. ${ }^{34}$ Pada 25 Oktober, mereka meneruskan perjalanan menuju ke Adrianople dan berjaya mengepung kubu kerajaan Uthmaniyah pada 29 Oktober manakala pada 31 Oktober tentera Bulgaria memohon bantuan daripada sekutunya Serbia untuk mengepung bahagian selatan Adrianople. ${ }^{35}$ Seterusnya, tentera bersekutu ini nekad untuk meneruskan operasi ketenteraan mereka untuk menyerang Constantinople.

Selain itu, tentera sekutu ini juga telah bergabung untuk menawan Macedonia. Tentera Bulgaria dan Serbia masing-masing bertempur dengan kerajaan Uthmaniyah dari bahagian utara dan timur Macedonia. Pada 22 November 1912, keseluruhan Macedonia jatuh ke tangan kuasakuasa kecil ini. Serbia dan sekutunya telah mencapai kejayaan yang besar di Macedonia dan Albania.

Di Albania, pada 22 Oktober 1912 tentera Serbia dan Montenegro berjaya menawan Kosovo. Penawanan Kosovo oleh Serbia dianggap sebagai kejayaan yang membanggakan kepada Serbia kerana menewaskan kerajaan Uthmaniyah dalam tahun 1463 di Kosovo. Oleh itu, kejayaan tentera Serbia di Kosovo berjaya menebus semula maruah Serbia. Bagi Montenegro, kejayaan memasuki Sanjak, Janina dan Scutari di Albania merupakan antara kejayaan terbesar pada ketika itu. Greek pula bertungkus lumus menentang kerajaan Uthmaniyah untuk menawan Salonika. Pada 14 November, Greek mengumumkan secara rasmi pengambilan Salonika oleh tenteranya daripada kerajaan Uthmaniyah di samping berjaya menewaskan kerajaan Uthmaniyah di beberapa pulau Laut Aegean. ${ }^{36}$

\section{Perang Balkan 1 dan Penyelesaian}

Kejayaan kuasa-kuasa Balkan adalah untuk mendapatkan wilayahwilayah Balkan, menggugat kedaulatan kerajaan Uthmaniyah serta menimbulkan kegelisahan terhadap kuasa-kuasa besar Eropah. Contohnya kejatuhan Constantinople turut menimbulkan tentangan dari Rusia kerana Rusia tidak dapat menerima kejayaan Bulgaria di Constantinople. Selain itu, kejayaan Bulgaria itu turut memalukan Rusia kerana Bulgaria merupakan sebuah kuasa kecil yang berjaya menawan Constantinople.

Oleh itu, Rusia mengumumkan kepada Bulgaria bahawa Rusia tidak mengiktiraf penawan Adrianople dan meminta Bulgaria supaya berundur daripada Constantinople. Kerajaan Rusia turut meminta supaya Bulgaria mengadakan gencatan senjata dengan kerajaan Uthmaniyah. Walau bagaimanapun, kerajaan Rusia mengakui bahawa mereka mengiktiraf kejayaan Bulgaria di utara Macedonia yang ditawan 
pada 19 Oktober 1912. Amaran daripada Rusia ini dinyatakan dari awal kepada Bulgaria supaya tidak berperang dengan kerajaan Uthmaniya. Tambahan pula, Rusia mula mengetahui akan kempen ketenteraan Bulgaria yang ingin menguasai Adrianople. ${ }^{37}$

Diplomasi dari sudut politik yang diutarakan oleh Rusia ini telah mempengaruhi tindakan Bulgaria. Permintaan daripada Rusia secara langsung menghalang keinginan Bulgaria untuk mara ke Constantinople. Bulgaria terpaksa bersetuju dengan permintaan Rusia kerana Bulgaria menghargai jasa Rusia yang telah membebaskan kerajaan Bulgaria pada 1878 daripada empayar Uthmaniyah dalam peperangan RusiaUthmaniyah. Malah, kerajaan Rusia juga memberikan bantuan dari segi material dan sokongan diplomatik kepada Bulgaria ketika menghadapi kerajaan Uthmaniyah dalam peperangan tersebut sebagai salah satu sekutu Rusia di Balkan. ${ }^{38}$

Kejayaan Serbia dan Montenegro di Macedonia dan Albania pula menimbulkan keresahan pada Austria-Hungary dan Itali. Mengikut Count Berctold ${ }^{39}$, kemaraan Serbia yang telah menembusi Albania perlu dihalang. Halangan yang dilakukan secara langsung mampu mengelak kuasa tersebut tidak akan mendapat pelabuhan di Laut Adriatik yang boleh membahayakan kedudukan Austria-Hungary. Pelabuhan di Adriatik boleh digunakan sebagai tapak oleh Rusia yang merupakan penaung Slav di Balkan. Selain itu, pelabuhan itu juga merupakan satu aset utama kepada Serbia untuk menutup laluan kepada kapal perdagangan Austria-Hungary. ${ }^{40}$

Oleh yang demikian, kuasa-kuasa besar telah meminta supaya kuasa-kuasa kecil ini menghentikan peperangan dengan kerajaan Uthmaniyah. Selain itu, di pihak kuasa-kuasa kecil ini pula, tentera Bulgaria juga tidak dapat meneruskan serangan lagi terhadap kerajaan Uthmaniyah kerana keadaan cuaca yang sejuk. Pada 3 Disember 1912, kerajaan Bulgaria bersetuju untuk menandatangani gencatan senjata dengan kerajaan Uthmaniyah. ${ }^{41}$

Persidangan secara rasminya akan diadakan di London bermula pada 16 Disember 1912. Persidangan tersebut dipengerusikan oleh Sir Edward Grey. Tujuan persidangan ini adalah untuk menghentikan Perang Balkan daripada merebak menjadi peperangan umum di Eropah. Persidangan ini turut dikenali sebagai St. James Conference. Berdasarkan persidangan, beberapa sasaran matlamat akan dicapai antaranya cadangan Austria-Hungary diterima oleh kuasa-kuasa besar untuk memberikan wilayah berautonomi ke atas Albania di bawah naungan kuasa-kuasa besar Eropah. Kedua, tidak ada sebarang perubahan sempadan wilayah antara Albania dan Montenegro dan saiz wilayah Albania akan dikekalkan. ${ }^{42}$ Manakala, tuntutan Serbia mendapat sebarang wilayah di Albania yang akan membolehkan 
kerajaan itu menguasai laluan ke Adriatik tidak dipersetujui oleh kerajaan Austria-Hungary dan tidak diputuskan oleh kuasa-kuasa besar.

Tatkala kuasa-kuasa besar sedang berusaha untuk mengelakkan peperangan tersebut, pada 30 Januari Bulgaria memaklumkan kepada Uthmaniyah, bahawa gencatan senjata dibatalkan. ${ }^{43} \mathrm{Hal}$ ini disebabkan kerajaan Uthmaniyah enggan menyerahkan Adrianople dan wilayah di Laut Aegean kepada kuasa-kuasa kecil. Oleh yang demikian, kuasakuasa kecil meneruskan usaha memerangi kerajaan Uthmaniyah. Pada 6 Mac 1912, kubu Uthmaniyah di Janina jatuh ke tangan Greek. Manakala, kerajaan Uthmaniyah pula sekali lagi gagal mempertahankan benteng mereka sehingga pada 26 Mac Adrianople dirampas oleh Bulgaria. Selain itu, pada 31 Mac Montenegro telah melancarkan serangan ke atas Scutari. Akhirnya, pada 23 April Scutari jatuh ke tangan Montenegro dengan bantuan Serbia. ${ }^{44}$ Keadaan ini menyebabkan Uthmaniyah serta merta memohon campurtangan kuasa-kuasa besar untuk menghentikan peperangan.

Selain itu, penawanan Scutari oleh Montenegro mendapat tentangan daripada kuasa-kuasa besar. Ini kerana pada 21 Mac 1913, kuasa-kuasa besar telah menetapkan bahawa Scutari ialah hak milik Albania selaras dengan pemberian autonomi kepada Albania. AustriaHungary memandang serius pencerobohan Montenegro ke atas Scutari. Sejak serangan Montenegro ke atas Scutari, Austria-Hungary telah mendesak rakan-rakan Eropahnya, mengambil berat isu pencerobohan Scutari oleh Montenegro. Malah, kuasa-kuasa besar juga telah bersetuju untuk melancarkan tunjuk perasaan tentera laut pada $31 \mathrm{Mac}$, sebagai memprotes tindakan Montenegro menyerang Scutari. ${ }^{45}$

Selain itu, Itali juga telah bersiap sedia untuk melancarkan operasi ketenteraan ke atas Montenegro di Albania. Ini kerana, Albania merupakan wilayah yang menjadi kepentingan kepada Austria-Hungary dan Itali. Oleh yang demikian, tekanan daripada kuasa-kuasa besar akhirnya memaksa Montenegro mengundurkan diri dari bandar Scutari pada 4 Mei $1913 .{ }^{46}$ Gencatan senjata diadakan sekali lagi dan perundingan diteruskan di London. Namun begitu, rundingan keamanan yang berlangsung di London tidak berjalan lancar seperti yang diharapkan oleh kuasa-kuasa besar. Ini kerana, perebutan wilayah antara kuasa-kuasa kecil mengenai pembahagian wilayah yang telah dirampas daripada kerajaan Uthmaniyah telah berlaku. Mereka bertelagah sesama mereka untuk merebut hak masing-masing dalam wilayah Uthmaniyah yang dirampas di Balkan. ${ }^{47}$

Masalah utama sukar dicapai dalam proses perdamaian yang dianjurkan oleh Sir Edward Grey ialah mengenai Bulgaria dan Serbia. Serbia enggan menandatangani perjanjian perdamaian disebabkan wujudnya perbalahan dengan Bulgaria mengenai pembahagian wilayah 
di Macedonia. Menurut Serbia, mereka juga berkorban membantu Bulgaria mendapatkan Macedonia. Bagi pandangan negara tersebut, kegagalannya mendapatkan Albania kerana campurtangan kuasa-kuasa besar tidak seharusnya ditanggung oleh Serbia sendirian sebaliknya harus dikongsi bersama Bulgaria dan sekutunya yang lain..$^{48}$ Oleh itu, Serbia telah membuat tuntutan kepada Bulgaria untuk mendapatkan wilayah Monastir, Prilep dan Ochrida di Macedonia. ${ }^{49}$ Sementara itu, di pihak Bulgaria pula mereka juga tidak berpuas hati dengan Serbia yang ingin merampas Macedonia daripadanya. Ini kerana dalam perjanjian Bulgaria-Serbia 1912 jelas bahawa Macedonia akan menjadi milik kerajaan Bulgaria melainkan bahagian utaranya sahaja. Selain itu, wujud juga pergolakkan antara Bulgaria dan Greek ke atas Salonika. Bulgaria juga enggan menyerahkan Salonika kepada Greek. Keengganan Bulgaria menyerahkan beberapa wilayah tersebut mencetuskan permusuhan antara kuasa-kuasa kecil ini dan mengganggu proses perdamaian.

Sikap Serbia lebih kepada memberi tumpuan dan perhatian kepada pertahanan wilayah yang menjadi rebutan antara mereka dengan Bulgaria berbanding menandatangani perjanjian perdamaian. Serbia terus mengekalkan tenteranya di wilayah-wilayah tuntutannya. Bagi Serbia, sekiranya Bulgaria ingin mengambil wilayah-wilayah tersebut, Bulgaria perlu berdepan dengan tentera Serbia. ${ }^{50}$ Serbia berharap dengan menangguhkan perjanjian perdamaian dengan Bulgaria, mampu memaksa Bulgaria menyerahkan wilayah-wilayah tersebut kepadanya. Greek juga bersama-sama Serbia enggan menandatangani perjanjian perdamaian yang diusahakan oleh Grey, ${ }^{51}$ selagi tuntutannya ke atas Salonika dan Laut Aegean tidak dipenuhi oleh Bulgaria.

Bagi pihak Bulgaria, kerajaannya ingin menyelesaikan perjanjian perdamaian mengenai sempadan antaranya dengan Uthmaniyah seberapa segera. Ini kerana kelewatan menandatangani perjanjian perdamaian secara rasmi menyebabkan Bulgaria terpaksa meletakkan tenteranya lebih lama di wilayah-wilayah yang dirampas selain terpaksa mengeluarkan perbelanjaan yang besar bagi tujuan tersebut. Namun begitu, keengganan Serbia dan Greek untuk menandatangani perjanjian menyebabkan persetujuan tidak dapat dicapai antaranya dengan kerajaan Uthmaniyah. Oleh itu, Bulgaria telah memohon kepada Sir Edward Grey supaya mempercepatkan urusan menandatangani perjanjian secara rasmi antaranya dengan kerajaan Uthmaniyah sekiranya sekutu-sekutunya yang lain enggan berbuat demikian. ${ }^{52}$

Manakala bagi kuasa-kuasa besar pula, mereka tidak berminat untuk campurtangan dalam masalah dalaman kuasa-kuasa kecil ini. Matlamat utama mereka adalah untuk membuat penyelesaian tentang sempadan antara kerajaan Uthmaniyah dengan negeri-negeri di Balkan. Britain sendiri berpendapat supaya masalah kuasa-kuasa kecil ini harus 
diselesaikan sesama mereka. ${ }^{53}$ Bagi Britain, kerajaannya dan rakan-rakan Eropahnya yang lain menunggu untuk satu tempoh yang cukup lama kepada Serbia dan Greek bagi mencapai persetujuan. Akhirnya, dalam pertemuan dengan delegasi-delegasi kerajaan Bulgaria, Serbia, Greek dan Uthmaniyah di London pada 27 Mei 1912, Sir Edward Grey telah mengeluarkan kenyataan bahawa "for those who were not prepared to sign to leave London, as it was no use their remaining for negotiations that led to nothing. Our own moral support would be given to those signed. "54

Kenyataan Sir Edward Grey yang merupakan ugutan kepada kuasa-kuasa kecil ini telah berjaya mempengaruhi mereka. Mereka bimbang sekiranya keengganan mematuhi arahan tersebut mampu menyebabkan kerajaan mereka tersingkir daripada sokongan kuasakuasa besar. Justeru, kenyataan tersebut telah memberi tekanan kepada Serbia dan Greek. Keadaan ini juga telah menyebabkan mereka terpaksa menandatangani perjanjian perdamaian pada 30 Mei 1913. Perjanjian yang dikenali sebagai Perjanjian London itu berjaya secara rasminya mengakhiri peperangan antara kuasa-kuasa Balkan dengan kerajaan Uthmaniyah.

Antara isi kandungan Perjanjian London yang lain adalah pengekalan kuasa kerajaan Uthmaniyah ke atas Constantinople dan juga selat-selat Bosphorus dan Dardanelles. Manakala Albania pula telah mendapat kemerdekaan di bawah naungan keenam-enam kuasakuasa besar Eropah. ${ }^{55}$ Perjanjian London ini lebih memberikan tumpuan kepada penyelesaian antarabangsa yang melibatkan kedudukan dan hak kuasa-kuasa besar. Antaranya mereka hanya menyelesaikan masalah sempadan antara kerajaan Uthmaniyah dengan negeri-negeri Balkan. Perjanjian ini juga jelas mengecilkan empayar kerajaan Uthmaniyah seperti mana perjanjian-perjanjian sebelum ini. Selain itu, kuasa-kuasa besar juga berminat mengenai penyelesaian mengenai Albania. Ini kerana, Itali dan Austria-Hungary juga mempunyai kepentingan dan minat yang sama di Albania. Oleh itu, status Albania seharusnya dijelaskan agar tidak menimbulkan konflik dan peperangan antara Serbia, Itali dan Austria-Hungary.

Sekiranya dilihat dari satu segi yang lain, Perjanjian London dan perebutan wilayah di Macedonia antara Serbia, Greek dan Bulgaria tidak dapat menyelesaikan isu tempatan di negeri-negeri Balkan. Kuasa-kuasa kecil hanya dipaksa untuk bersetuju menghentikan peperangan dan menandatangani perjanjian keamanan dengan kerajaan Uthmaniyah. Sebaliknya, wilayah-wilayah yang dirampas daripada kerajaan Uthmaniyah dalam peperangan tersebut tidak dibuat pembahagiannya kepada kuasa-kuasa kecil secara jelas dan rasmi. Ini menyebabkan mereka yang terlibat dalam peperangan tersebut bermusuhan antara satu sama lain untuk mendapatkan wilayah yang 
telah dirampas sebagai hak milik mereka. Permusuhan ini berlarutan sehingga membawa kepada sekali lagi peperangan di Balkan yang dikenali sebagai Perang Balkan 2 iaitu pada bulan Jun 1913.

\section{Kesimpulan}

Jelas memperlihatkan bahawa perjanjian Liga Balkan 1912 secara langsung menyebabkan kuasa-kuasa kecil Balkan bersetuju untuk bersama-sama mengusir kerajaan Uthmaniyah di Balkan dan kemudiannya empayar Austria-Hungary. Peperangan ini membuktikan bahawa kuasa-kuasa kecil ini telah mampu berdikari dari segi ketenteraan sehingga boleh melancarkan serangan ke atas musuh mereka tanpa bantuan daripada kuasa-kuasa besar. Kejayaan mereka menewaskan kerajaan Uthmaniyah terutama di Albania dan Adrianople ternyata membimbangkan kuasa-kuasa besar terutamanya Rusia dan Austria-Hungary. Ini menyebabkan kuasa-kuasa besar terpaksa campurtangan untuk memberhentikan peperangan. Oleh itu, kuasakuasa kecil ini terpaksa bersetuju dengan cadangan kuasa-kuasa besar untuk berdamai dengan kerajaan Uthmaniyah pada Disember 1912 bertempat di St. James, London.

Namun, gencatan senjata dibatalkan oleh Bulgaria pada Januari 1913, apabila tuntutannya untuk menguasai Adrianople tidak dipenuhi oleh Uthmaniyah. Selain masalah Bulgaria dengan kerajaan Uthmaniyah, Bulgaria juga menghadapi masalah dengan sekutu-sekutunya mengenai pembahagian wilayah yang dirampas daripada kerajaan Uthmaniyah. Perebutan sesama kuasa-kuasa kecil ini berlarutan sehingga bulan Mei 1913. Ini disebabkan tindakan Sir Edward Grey yang mendesak kuasakuasa kecil mempercepatkan menandatangani perjanjian damai dengan kerajaan Uthmaniyah tanpa persetujuan mereka tentang pembahagian wilayah yang dirampas daripada Uthmaniyah. Mereka terpaksa menandatangani perjanjian dengan kerajaan Uthmaniyah pada $30 \mathrm{Mei}$ 1913 yang dikenali sebagai Perjanjian London. Perjanjian yang dibuat atas inisiatif Sir Edward Grey berjaya menamatkan masalah tentang status Albania di Balkan. Namun, kelemahan perjanjian tersebut tidak menyentuh tentang pembahagian rampasan wilayah yang diambil daripada kerajaan Uthmaniyah oleh kuasa-kuasa kecil.

Kelemahan inilah yang menyebabkan mereka tidak berpuas hati antara satu sama lain. Serbia dan Bulgaria mendakwa bahawa Macedonia adalah hak mereka. Ini menyebabkan peperangan di Balkan yang berlaku sekali lagi tidak dapat dielakkan dan seterusnya mencetuskan Perang Balkan 2 antara Serbia dan Bulgaria pada Mei 1913 iaitu dua bulan selepas termeterainya Perjanjian London 1913. Perang Balkan 2 sekali lagi membawa kejayaan kepada Serbia. 
Ini menjadikan Serbia semakin berbangga kerana mempunyai angkatan tentera yang kuat di Balkan dan semakin berdendam dengan Austria-Hungary akibat krisis Bosnia 1908 dan kemerdekaan Albania. Krisis yang berlaku secara langsung menyebabkan persaingan antara kedua-duanya masih belum selesai sebaliknya menjadi semakin kronik sehingga pegawai-pegawai kerajaan Serbia sanggup berkomplot untuk bertindak ganas terhadap keluarga Diraja Austria-Hungary pada tahun 1914 yang sekaligus mengheret kuasa-kuasa besar Eropah ke kancah Perang Dunia 1.

\section{Nota}

1 FO424/234, Surat Sir R.Paget kepada Sir Edward Grey, Belgrade, 15 Ogos 1912.

Ibid.

Perjanjian Persahabatan dan Persekutuan di antara Kerajaan Bulgaria dan Kerajaan Serbia, Appendix V, 29 Februari 1912 dalam G.P.Gooch and Harold Temperley (eds), British Documents on the Origins of The War 1898-1914, USA: Johnson Reprint Corporation, 1967, Vol. IX, Part II, hlm. 391.

$4 \quad$ Ibid.

5 The Balkan Alliance, Appendix II dalam G.P.Gooch and Harold Temperley(eds), British Documents on the Origins of The War 1898-1914, USA: Johnson Reprint Corporation, 1967, Vol. IX, Part II, hlm. 1006.

Ibid.

Raja Montenegro atau nama sebenarnya Nicholas Petrovic menjadi Putera Mahkota kerajaan Montenegro pada tahun 1860-1910. Beliau memerintah Montenegro dari tahun 1910-1918.

$8 \quad$ Tripoli merupakan jajahan kerajaan Kristian Katolik sebelum jatuh ke tangan kerajaan Uthmaniah. Itali ingin mengambil Tripoli atas sebab keagamaan. Itali pernah cuba mendapatkan Tripoli pada tahun 1890 tetapi gagal mendapat sokongan Britain dan Perancis. Tripoli merupakan tanah jajahan terakhir yang tinggal di bawah kerajaan Uthmaniah di Afrika Utara dan merupakan negeri yang miskin. Oleh sebab itu, kuasakuasa besar yang lain tidak berminat dengan Tripoli. Perancis hanya membenarkan Itali mengambil Tripoli pada 1900 setelah Moroko jatuh ke tangan Perancis. Manakala pada 1902, Itali mendapat kebenaran menjelajah Tripoli daripada Austria-Hungary dan Britain. Rusia juga memberi kebenaran tersebut kepada Itali pada 1909 sebagai jaminan Itali akan menyokong Rusia mengenai selat-selat di Laut Hitam. Atas sebabsebab tersebut, Itali mengisytiharkan perang ke atas kerajaan Uthmaniah pada 1911 bertujuan untuk mendapatkan Tripoli.

$9 \quad$ FO 424/234, Surat Sir F.Bertie kepada Sir Edward Grey, Paris, 29 Ogos 1912.

10 FO 424/234, Surat Sir R.Paget kepada Sir Edward Grey, Belgrade, 15 Ogos 1912.

11 Ibid. 
12 FO 424/234, Surat Sir G. Buchanan kepada Sir Edward Grey, St.Petersburgh, 22 Ogos 1912.

13 FO 424/234, Surat Sir F.Bertie To Sir Edward Grey, Paris, 31 Ogos 1912.

14 FO 424/234, Surat Sir Edward Grey kepada Sir F.Bertie, Foreign Office, 20 September 1912.

15 FO 424/234, Surat Sir R.Paget kepada Sir Edward Grey, Belgrade, 23 September 1912.

16 FO 424/234, Surat Sir Barclay kepada Sir Edward Grey, Sophia, 22 September 1912.

17 FO 424/234, Surat Sir Barclay kepada Sir Edward Grey, Sophia, 30 September 1912.

18 FO 424/234, Surat Sir Edward Grey kepada Sir F.Bertie, Foreign Office, 9 Oktober 1912.

19 Ibid.

20 FO 424/234, Surat Mr.Barclay kepada Sir Edward Grey, Sophia, 18 September 1912.

Surat Sir R. Paget kepada Sir Edward Grey, No 79, Belgrade, 30 Oktober 1912 dalam G.P.Gooch and Harold Temperley (eds), British Documents on The Origins of The War 1898-1914, USA: Johnson Reprint Corporation, 1967, Vol. IX, Part II, hlm. 66. FO 424/234, Surat Sir G. Buchanan kepada Sir Edward Grey, St.Petersburgh, 28 Ogos 1912. FO 424/234, Surat Sir Edward Grey kepada Sir Marling, Foreign Office, 28 Ogos 1912. FO 424/234, Surat Count De Salis kepada Sir Edward Grey,Cettinge, 20 Ogos 1912. FO 424/234, Surat Sir G. Buchanan kepada Sir Edward Grey, St.Petersburgh, 19 September 1912. FO 424/234, Surat Mr. Barclay kepada Sir Edward Grey, Sophia, 14 Ogos 1912. FO 424/234, Surat Sir H. Bax Ironside kepada Sir Edward Grey, Sophia, 8 Oktober 1912. FO 424/234, Surat Sir R. Paget kepada Sir Edward Grey, Belgrade, 9 Oktober 1912. FO 424/234, Surat Sir M.Gennadius kepada Sir Edward Grey, Greek Legation, 18 Oktober 1912. FO 424/234, Surat Sir R. Paget kepada Sir Edward Grey, 30 September 1912. FO 371/1518, Surat Sir R. Paget kepada Sir Edward Grey, Belgrade, 21 Disember 1912. FO 424/234, Surat Sir F. Bertie kepada Sir Edward Grey, Paris, 13 Oktober 1912.

33 FO 424/235, Surat Sir G. Lowther kepada Sir Edward Grey, Constantinople, 3 November 1912.

34 FO 424/235, Surat Sir G. Buchanan kepada Sir Edward Grey, St.Petersburgh, 5 November 1912. 
FO 424/235, Surat Sir Bax Ironside kepada Sir Edward Grey, Sophia, 1 November 1912.

36 FO 424/235, Surat Sir F.Elliot kepada Sir Edward Grey, Athens, November 16,1912 .

37 FO 424/234, Surat Sir G.Buchanan kepada Sir Edward Grey, St. Petersburgh, 18 September 1912.

38 Ibid.

39 Nama penuh beliau ialah Berchtold, Leopold Anton Johann Sigismund Joseph Korsinus Ferdinand. Dilahirkan pada tahun 18 April 1863. Beliau merupakan seorang tuan tanah yang kaya raya di Hungary dan merupakan salah seorang jutawan Austria Hungary. Beliau menceburi bidang politik pada tahun 1893 sebagai pegawai diplomatik yang dilantik bertugas di Paris dan London. Pada tahun 1906, beliau telah dilantik sebagai duta Austria Hungary ke Rusia. Seterusnya pada tahun 1912 iaitu selepas kematian Baron Aehrenthal beliau dilantik untuk memegang jawatan sebagai Menteri Luar Austria Hungary menggantikan Aehrenthal. FO 424/234, Surat Sir G. Buchanan kepada Sir Edward Grey, St. Petersburgh, 18 September 1912.

$41 \quad$ Nota komunikasi oleh M. Majarov, No. 332, London, 4 Disember 1912 dalam G.P.Gooch and Harold Temperley (eds), British Documents on the Origins of The War 1898-1914, USA: Johnson Reprint Corporation, 1967, Vol. IX, Part II, hlm. 248.

42 Surat Sir Edward Grey kepada Sir F.Cartwright, No. 391, Foreign Office, 17 Disember 1912, dalam G.P.Gooch and Harold Temperley (eds), British Documents on the Origins of The War 1898-1914, USA: Johnson Reprint Corporation, 1967, Vol. IX, Part II, hlm. 292.

43 Surat Sir Edward Grey kepada Sir.F.Bertie, No. 576, Foreign Offce, 30 Januari 1913, dalam G.P.Gooch and Harold Temperley (eds), British Documents on the Origins of The War 1898-1914, USA: Johnson Reprint Corporation, 1967, Vol. IX, Part II, hlm. 461.

44 Surat Count de Salis kepada Sir Edward Grey, No. 872, Cettinge, 23 April 1913, dalam G.P.Gooch and Harold Temperley (eds), British Documents on the Origins of the War 1898-1914, USA, Johnson reprint corporation, 1967, Vol. IX, Part II, hlm. 709.

45 Komunikasi oleh Count Mensdorff, Austro Hungarian Embassy, No. 768, London, 31 Mac 1913, dalam G.P.Gooch and Harold Temperley (pnyt.), British Documents on the Origins of the War 1898-1914, USA: Johnson reprint corporation, 1967, Vol. IX, Part II, hlm. 626.

46 Surat Count de Salis kepada Sir Edward Grey, No. 947, Cettinge, 4 Mei 1913, dlm. G.P.Gooch and Harold Temperley (eds), British Documents on the Origins of The War 1898-1914, USA: Johnson Reprint Corporation, 1967, Vol. IX, Part II, hlm. 766.

$47 \quad$ Ibid.

48 FO 371/1798, Surat Sir H.Bax Ironside kepada Sir Edward Grey, Sophia, 22 Mei 1913.

49 Surat Sir R.Paget kepada Sir Edward Grey, No. 959, Belgrade, 6 Mei 1913, dalam G.P.Gooch and Harold Temperley (eds), British Documents on the 
Origins of The War 1898-1914, USA: Johnson Reprint Corporation, 1967, Vol. IX, Part II, hlm. 775.

50 Surat Sir R.Paget kepada Sir Edward Grey, No. 978, Belgrade, 16 Mei 1913, dalam G.P.Gooch and Harold Temperley (eds), British Documents on the Origins of The War 1898-1914, USA: Johnson Reprint Corporation, 1967, Vol. IX, Part II, hlm. 795.

51 Nama sebenar beliau ialah Edward Grey. Beliau dilahirkan pada 25 April 1862 di London. Beliau merupakan negarawan Britain yang menjawat jawatan paling lama sebagai Setiausaha Luar Britain iaitu selama 11 tahun. Grey memulakan kariernya sebagai Setiausaha Luar Britain pada 1905 di bawah Perdana Menteri Sir Henry Campbell Bannerman.

52 FO 881/10418, Surat Sir Edward Grey kepada Sir H.Bax - Ironside, Foreign Office, 26 Mei 1913.

53 Surat Sir H.Bax Ironside kepada Sir Edward Grey, No. 881, Sofia, 29 April 1913, dalam G.P.Gooch and Harold Temperley (eds), British Documents on the Origins of The War 1898-1914, USA: Johnson Reprint Corporation, 1967, Vol. IX, Part II, hlm. 714.

54 FO 881/10418, Surat Sir Edward Grey kepada Sir R.Paget, Foreign Office, 27 Mei 1913.

55 Hurst Micheal, Key Treaties For The Great Powers 1814-1914, New Ton Abbot: David \&Charles, 1972, hlm. 853. 